Bull. Chem. Soc. Ethiop. 2017, 31(3), 509-518.

ISSN 1011-3924

(c) 2017 Chemical Society of Ethiopia and The Authors

Printed in Ethiopia

DOI: http://dx.doi.org/10.4314/bcse.v31i3.15

\title{
THE USE OF OPTICALLY ACTIVE O-ALKYL ESTER HYDROCHLORIDES OF L- PHENYLALANINE AND L-TYROSINE AS CHIRAL MICELLAR MEDIA FOR THE CATALYSIS OF DIELS-ALDER REACTIONS
}

\author{
P. Caumul", P. Koonja, N. Namooya, A. Prayag, N. Joondan and S. Jhaumeer-Laulloo \\ Department of Chemistry, Faculty of Science, University of Mauritius, Réduit, Mauritius
}

(Received March 7, 2017; Revised December 15, 2017; Accepted December 18, 2017)

\begin{abstract}
The effect of a range of $O$-alkyl ester hydrochloride surfactants derived from L-phenylalanine and L-tyrosine as catalysts on the Diels-Alder reaction between cyclopentadiene and methyl acrylate was studied. Both chain lengths $\left(\mathrm{C}_{8}-\mathrm{C}_{14}\right)$ and head groups of the surfactants were found to influence the yield and selectivity of the Diels-Alder product. The $\mathrm{C}_{10}$ derivatives of both phenylalanine and tyrosine surfactants gave the highest yields and selectivity. Phenylalanine ester hydrochlorides showed better catalytic activity than the tyrosine derivatives. Adduct optimum yield was obtained at a concentration relating to their critical micelle concentration (CMC) values. The Diels-Alder reaction was also found to be favored in acidic condition ( $\mathrm{pH} 3$ ) as well as in the presence of lithium chloride $(\mathrm{LiCl})$ as salting out agent.
\end{abstract}

KEY WORDS: Diels-Alder, Chiral catalysts, Phenylalanine, Tyrosine, Micelle, CMC

\section{INTRODUCTION}

The Diels-Alder reaction is one of the most important carbon-carbon bond forming reactions and has been involved in key steps in the making of important intermediates that leads to the synthesis of anti-cancer and anti-viral drugs such as Taxol and Tamiflu, respectively $[1,2]$. Since then, Diels-Alder reactions have formed an important part of the synthetic repertoire of making intermolecular and intramolecular cyclic compounds.

Different strategies of enhancing asymmetric Diels-Alder reactions have been reported [3, 4]. With this view, the choice of catalyst to enhance the yield and selectivity of Diels-Alder reactions has also been an important issue that needs to be addressed [5,6]. Catalysts such as Lewis acids $[7,8]$ have been known to enhance Diels-Alder reactions but their use has been restricted since they decompose in the presence of a small amount of water and cannot be reused [9].

The use of surfactants in assisting a variety of organic reactions is highly promising for basic and applied research $[10,11]$. Micelle forming surfactants have been widely used as reaction medium for many important organic reactions since micelles form organized assemblies that affect the rates of chemical reactions and the position of chemical equilibrium $[12,13]$. The use of surfactants in micellar medium offers the possibilities for reaction control due to special properties such as solubilization, pre-orientation, microviscosity, polarity and charge effects that surfactants can confer [14]. These effects influence the organic reactions by affecting the yield, regio and stereochemistry of the products.

The idea of micellization for the rate-enhancement of Diels-Alder reactions dates back to the 1980 s, where higher yields were obtained when using water as solvent compared to other nonpolar solvents [15-18]. Hence, surfactants offer the possibility for organic reactions to occur in aqueous media, and from the viewpoint of green chemistry, water is safer, harmless and environmentally benign [19].

However, there has been limited work on the use of chiral micellar media to catalyze DielsAlder reactions. Amino acids are useful synthons from the chiral pool that help to provide a cost

*Corresponding author. E-mail: p.caumul@uom.ac.mu

This work is licensed under the Creative Commons Attribution 4.0 International License 
effective way of synthesizing surfactants as chiral catalysts. Optically active surfactants derived from $S$-leucine and phenylalanine have been reported to be effective catalysts for the reaction between nonyl acrylate and cyclopentadiene [20].

In continuation for the search of effective chiral micellar catalysts for Diels-Alder reactions, a range of pre-synthesized ester hydrochloride surfactants derived from L-phenylalanine and Ltyrosine [21] were used as novel chiral micellar-based catalysts for the reaction between methyl acrylate and cyclopentadiene. The effect of chain length and head groups of the surfactants on the reaction yields and selectivity were investigated. The reaction conditions such as concentration of surfactants, temperature, time and solvent variation were also studied in view of investigating the optimum conditions for which these surfactants can act as effective catalysts for the Diels-Alder reaction.

\section{EXPERIMENTAL}

L-Phenylalanine was obtained from HiMedia Laboratories (India). L-Tyrosine, octan-1-ol, decan-1-ol, dodecan-1ol, tetradecan-1-ol, dicyclopentadiene and thionyl chloride were purchased from Sigma-Aldrich (USA). $p$-Toluene sulfonic acid (PTSA) was obtained from Merck (Germany). Silica gel (60-120 Mesh) used for column chromatography was obtained from Alpha Chemika (India). Cetyltrimethyl ammonium bromide (CTAB) was obtained from BDH Laboratory Supplies (England). Sodium dodecyl sulfate was obtained from Loba Chemie (India).

${ }^{1} \mathrm{H}$ and ${ }^{13} \mathrm{C}$ NMR spectra were recorded at $250 \mathrm{MHz}$ and $62.9 \mathrm{MHz}$, respectively, on a Bruker electro spin NMR spectrometer using $\mathrm{CDCl}_{3}, \mathrm{D}_{2} \mathrm{O}$ and DMSO- $d_{6}$ as solvents. GC-MS analysis was carried out on a Clarus 500 GC-Clarus 560S Mass Spectrometer using an SGE BPX5 capillary column $(30 \mathrm{~m} \times 0.32 \mathrm{~mm} \times 0.5 \mu \mathrm{m})$, helium gas as carrier with a flow rate of $1.50 \mathrm{~mL} / \mathrm{min}$, injector temperature of $240{ }^{\circ} \mathrm{C}$, detector temperature of $270{ }^{\circ} \mathrm{C}$ and oven temperature program $100{ }^{\circ} \mathrm{C}$ (hold for $2 \mathrm{~min}$ ), ramp rate of $15{ }^{\circ} \mathrm{C} / \mathrm{min}$ to $280{ }^{\circ} \mathrm{C}$ (hold for 15 $\mathrm{min}$ ), flow rate $1.50 \mathrm{~mL} / \mathrm{min}$. The cycloadduct isomers were identified by matching their mass spectra with those in the NIST library. The order of product retention time of the isomers was determined from literature data [22].

\section{General method for the Diels-Alder reaction}

Cyclopentadiene was obtained by thermal cracking of dicyclopentadiene at $160{ }^{\circ} \mathrm{C}$. Cyclopentadiene $(0.32 \mathrm{~mL}, 3.80 \mathrm{mmol})$ and methyl acrylate $(0.17 \mathrm{~mL}, 1.90 \mathrm{mmol})$ were added to an aqueous solution of the surfactant and the reaction mixture was stirred at room temperature for 72 hours. The mixture was extracted with diethylether $(3 \times 20 \mathrm{~mL})$. The organic phase was dried over anhydrous sodium sulfate, filtered and the excess solvent was removed under vacuo to yield the crude Diels-Alder adduct which was purified by column chromatography using hexane/ethyl acetate in a ratio of 2:1. The pure product was obtained in $95 \%$ yield and was analyzed using GC/MS.

Methyl bicyclo [2.2.1] hept-5-ene-2-carboxylate. ${ }^{1} \mathrm{H} \mathrm{NMR}\left(\mathrm{CDCl}_{3}\right) \delta(\mathrm{ppm}): 1.23(1 \mathrm{H}, \mathrm{m}), 1.39$ $(2 \mathrm{H}, \mathrm{m}), 1.84(1 \mathrm{H}, \mathrm{m}), 2.90(2 \mathrm{H}, \mathrm{m}), 3.61(3 \mathrm{H}, \mathrm{s}), 5.90(1 \mathrm{H}, \mathrm{m}), 6.15-6.19(1 \mathrm{H}, \mathrm{m}) .{ }^{13} \mathrm{C} \mathrm{NMR}$ $\left(\mathrm{CDCl}_{3}\right) \delta(\mathrm{ppm}): 32.1\left(\mathrm{CH}_{2}\right), 45.4(\mathrm{C}-\mathrm{CO}), 46.0(\mathrm{CH}-\mathrm{CO}), 48.5\left(\mathrm{CH}_{2}\right), 52.5(\mathrm{CH}), 54.3(\mathrm{O}-$ $\left.\mathrm{CH}_{3}\right), 135.2(2 \mathrm{C}, \mathrm{C}=\mathrm{C}), 178.1(\mathrm{C}=\mathrm{O}) . \mathrm{m} / \mathrm{z}(\mathrm{EI}) 151.1873\left(\mathrm{M}^{+}, 30 \%\right)$. Retention times: $4.48 \mathrm{~min}$, exo-cycloadduct, $4.63 \mathrm{~min}$, endo-cycloadduct [lit: $12.7 \mathrm{~min}$, exo-cycloadduct; $12.9 \mathrm{~min}$, endocycloadduct] [23]. The endo/exo ratio was calculated based on the peak areas of the endo and exo-cycloadduct in the chromatogram. 


\section{RESULTS AND DISCUSSION}

The Diels-Alder reaction between methyl acrylate and cyclopentadiene gives rise to a mixture of exo (thermodynamic) and endo (kinetic) products (Figure 1) [23]. The reaction was initially carried out in the presence of the commercially available surfactant cetyltrimethyl ammonium bromide $(\mathrm{CTAB})$ in water.

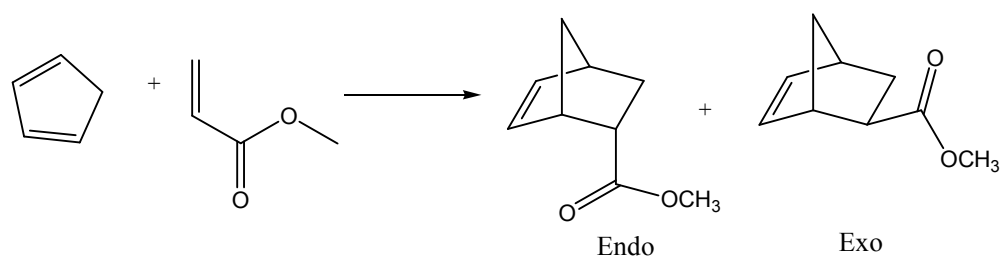

Figure 1. Diels-Alder reaction between methyl acrylate and cyclopentadiene.

The presence of $\mathrm{CTAB}$ afforded higher product yield compared to the reaction where no catalyst was used. At the critical micelle concentration (CMC), which is the concentration at which surfactant monomers cyclize to form micelles, an increase in product yield of up to $95 \%$, together with a lower endo-exo ratio were observed.

L-Phenylalanine and L-tyrosine $O$-alkyl ester hydrochloride surfactants of varying lengths $\left(\mathrm{C}_{8}\right.$ to $\left.\mathrm{C}_{14}\right)$ (Figure 2 ) which have been previously synthesized by our group were tested as potential chiral micellar catalysts for the Diels-Alder reaction between methyl acrylate and cyclopentadiene.

\begin{tabular}{|c|c|c|c|c|}
\hline $\mathbf{n}$ & $\mathbf{8}$ & $\mathbf{1 0}$ & $\mathbf{1 2}$ & $\mathbf{1 4}$ \\
\hline $\mathrm{R}=\mathrm{H}$ & $\mathrm{Phe} 8$ & Phe 10 & Phe 12 & Phe 14 \\
\hline $\mathrm{R}=\mathrm{OH}$ & $\mathrm{Tyr} 8$ & Tyr 10 & Tyr 12 & Tyr 14 \\
\hline
\end{tabular}

Figure 2. L-Phenylalanine and L-tyrosine ester hydrochloride surfactants.

The studies were carried out at the CMCs of the surfactants and the results are summarized in Table 1 [21]. An increase in the yield of the Diels-Alder adduct was obtained as the chain length of the ester hydrochlorides was increased from $\mathrm{C}_{8}$ to $\mathrm{C}_{10}$ for both the phenylalanine (Table 1, entries 3 and 7) and tyrosine (Table 1, entries 16 and 20) series. This may be due to the increase in the hydrophobic character of the surfactant molecules which favors the interaction with the reacting substrates. The maximum catalytic efficiency was obtained with an alkyl chain length of $\mathrm{C}_{10}$ for both surfactants. However, a further increase in the chain length from $\mathrm{C}_{10}$ to $\mathrm{C}_{14}$ resulted in a decrease in the yield (Table 1, entries 14, 15, 27, 28) (Figure 3). This can be attributed to the coiling effect of the surfactant of higher chain lengths which can potentially alter the orientation of the substrates resulting in reduced yields [24]. An increase in the percentage of the endo adduct was observed with increasing chain length of phenylalanine alkyl esters while for tyrosine, the percentage of the endo adduct decreases from $\mathrm{C}_{8}$ to $\mathrm{C}_{10}$ and then increases from $\mathrm{C}_{12}$ to $\mathrm{C}_{14}$. 
Table 1. Reactions between cyclopentadiene and methyl acrylate carried out at the surfactants' CMC*

\begin{tabular}{|c|c|c|c|c|c|c|c|}
\hline Entry & Solvent & Surfactant & $\mathrm{CMC}^{*} \mathrm{mM}$ & Temp $\left({ }^{\circ} \mathrm{C}\right)$ & Time/h & Yield (\%) & Endo: Exo \\
\hline 1 & Water & - & & 20 & 72 & 18 & $85: 15$ \\
\hline 2 & Water & CTAB & 1.00 & 20 & 72 & 95 & $82: 18$ \\
\hline 3 & Water & Phe8 & 3.96 & 20 & 72 & 87 & $75: 25$ \\
\hline 4 & Water & Phe10 & 0.69 & 20 & 4 & 18 & $91: 9$ \\
\hline 5 & Water & Phe10 & 0.69 & 20 & 24 & 38 & $90: 10$ \\
\hline 6 & Water & Phe10 & 0.69 & 0 & 72 & 0 & - \\
\hline 7 & Water & Phe10 & 0.69 & 20 & 72 & 98 & $80: 20$ \\
\hline 8 & Hexane & Phe10 & 0.69 & 20 & 72 & 36 & $69: 31$ \\
\hline 9 & DCM & Phe10 & 0.69 & 20 & 72 & 0 & - \\
\hline 10 & THF & Phe10 & 0.69 & 20 & 72 & 63 & $73: 27$ \\
\hline 11 & Water & Phe10 & 0.69 & 40 & 72 & 61 & $86: 14$ \\
\hline 12 & Water & Phe10 & 0.69 & 70 & 72 & 27 & $89: 11$ \\
\hline 13 & Water & Phe10 & 0.69 & 100 & 72 & 18 & $83: 17$ \\
\hline 14 & Water & Phe12 & 0.154 & 20 & 72 & 72 & $81: 19$ \\
\hline 15 & Water & Phe14 & 0.180 & 20 & 72 & 64 & $89: 11$ \\
\hline 16 & Water & Tyr8 & 1.94 & 20 & 72 & 53 & $86: 14$ \\
\hline 17 & Water & Tyr10 & 0.180 & 20 & 4 & 10 & $86: 14$ \\
\hline 18 & Water & Tyr10 & 0.283 & 20 & 24 & 29 & $81: 19$ \\
\hline 19 & Water & Tyr10 & 0.283 & 0 & 72 & 15 & $85: 15$ \\
\hline 20 & Water & Tyr10 & 0.283 & 20 & 72 & 70 & $80: 20$ \\
\hline 21 & Hexane & Tyr10 & 0.283 & 20 & 72 & 30 & $71: 29$ \\
\hline 22 & DCM & Tyr10 & 0.283 & 20 & 72 & 0 & - \\
\hline 23 & THF & Tyr10 & 0.283 & 20 & 72 & 50 & $77: 23$ \\
\hline 24 & Water & Tyr10 & 0.283 & 40 & 72 & 40 & $91: 9$ \\
\hline 25 & Water & Tyr10 & 0.283 & 70 & 72 & 35 & $92: 8$ \\
\hline 26 & Water & Tyr10 & 0.283 & 100 & 72 & 0 & - \\
\hline 27 & Water & Tyr12 & 0.0388 & 20 & 72 & 44 & $85: 15$ \\
\hline 28 & Water & Tyr14 & 0.0138 & 20 & 72 & 34 & $85: 15$ \\
\hline
\end{tabular}

${ }^{*} \mathrm{CMC}$ was studied using conductivity measurements and has been previously published [21].

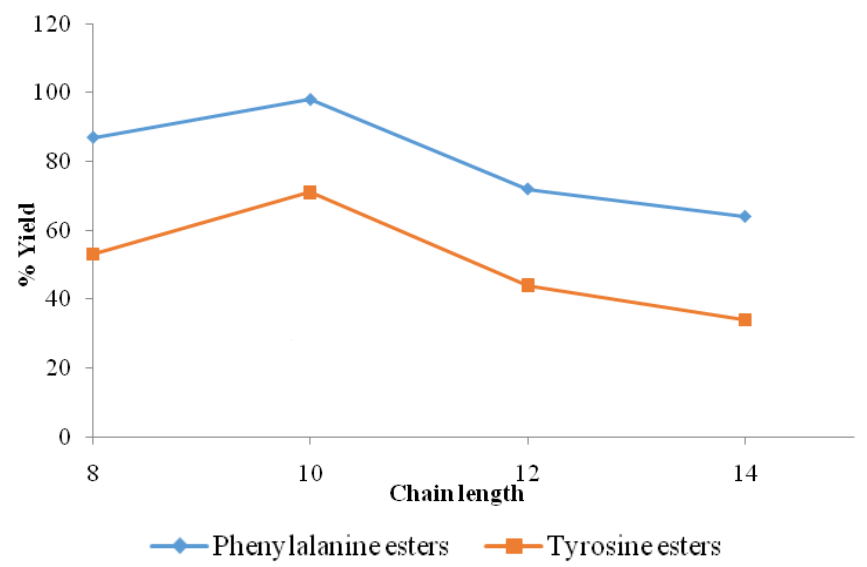

Figure 3. Effect of chain lengths of L-phenylalanine and L-tyrosine on reaction yields of the Diels-Alder adduct.

Bull. Chem. Soc. Ethiop. 2017, 31(3) 
The use of optically active $O$-alkyl ester hydrochlorides of L-phenylalanine and L-tyrosine 513

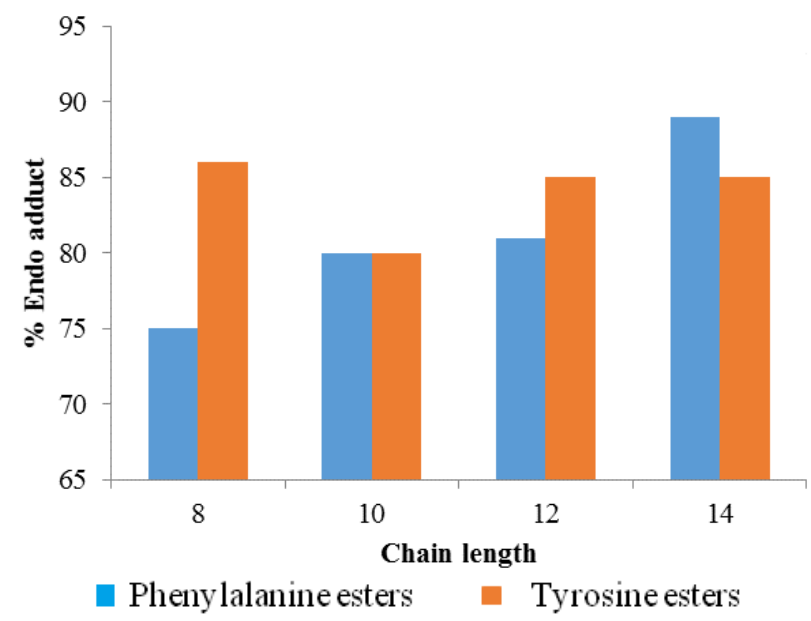

Figure 4. Effect of chain lengths of L-Phenylalanine and L-Tyrosine on reaction selectivity.

The yield of the Diels-Alder adduct was found to increase with the reaction time. At $72 \mathrm{~h}$, the cyclic adduct was obtained in 98 and $70 \%$ yield using the $\mathrm{C}_{10}$ derivatives of phenylalanine and tyrosine ester hydrochlorides respectively (Table 1, entries 7 and 20). When the Diels-Alder reaction was carried out for longer reaction times the endo:exo ratio was found to decrease. This is in line with what has been reported in literature, whereby longer reaction times cause retro reaction to occur readily, favoring the formation of the more thermodynamically stable exo product [23].

The optimum yield was obtained when the reaction was carried at $20{ }^{\circ} \mathrm{C}$ (Table 1 , entries 3 , $7,14,15,16,20,27,28)$. Increasing the temperature of the reaction beyond $20^{\circ} \mathrm{C}$ resulted in a change in the micellar structure of the catalyst which reduces the yield of the product and favoring at the same time the formation of the kinetic endo product [25].

The formation of the Diels-Alder adduct was found to be dependent on the nature of solvent. For both the tyrosine and phenylalanine hydrochloride surfactant series, increasing the polarity of the solvent from hexane to THF and to water caused an increase in the yield of the reaction. This is in line with what has been previously reported, where the use of aqueous media was found to enhance Diels-Alder reaction [26]. Non-polar solvents reduced both the yield and the selectivity (Table 1, entry 21) of the cycloadduct since reverse micelles are known to be formed in these media [27, 28]. Surprisingly, when DCM was employed using either tyrosine or phenylalanine hydrochloride the yield obtained was negligible (Table 1, entries 9 and 22). This is maybe due to the fact that the structural orientation of both Phe-10 and Tyr-10 surfactants under these conditions do not favourably interact with the reacting substrates. This is in line with Sousa's work who demonstrated how a variation of catalysts in DCM can affect the reaction yield as a result of how they interact with the reacting substrate [29].

From Table 1, it can be deduced that in general phenylalanine ester hydrochloride surfactants proved to be more of a potential chiral micellar catalyst than the tyrosine analogues in terms of both the yield and endo/exo ratio. This may be explained by the different orientations adopted at the micellar interface by the phenylalanine and tyrosine ester hydrochlorides. When the reacting substrates are introduced in the aqueous micellar solutions, dienes and dienophiles come in close proximity of the micellar structure causing them to bind within the micelles enhancing the reactivity. Therefore, the rate of reaction of surfactant-assisted catalysis for DielsAlder reactions in water will depend on the nature of surfactant, overall influence of 
hydrophobic effects, electrostatic interactions and the accompanying medium effects. In the case of phenylalanine esters, the phenyl ring remained folded away from the aqueous medium within the micellar core together with the hydrophobic tail allowing better $\pi$ - $\pi$-stacking between the aromatic ring and reacting substrates. In case of the tyrosine dodecyl ester hydrochloride, the $\mathrm{OH}$ moiety in tyrosine pulled the aromatic ring towards the aqueous layer thus causing less $\pi$ - $\pi$ stacking (Figure 5) [30-32]. Figure 5 shows how the reacting substrates may interact with phenylalanine and tyrosine dodecyl ester hydrochlorides which has led to the different yields and endo/exo behaviors.
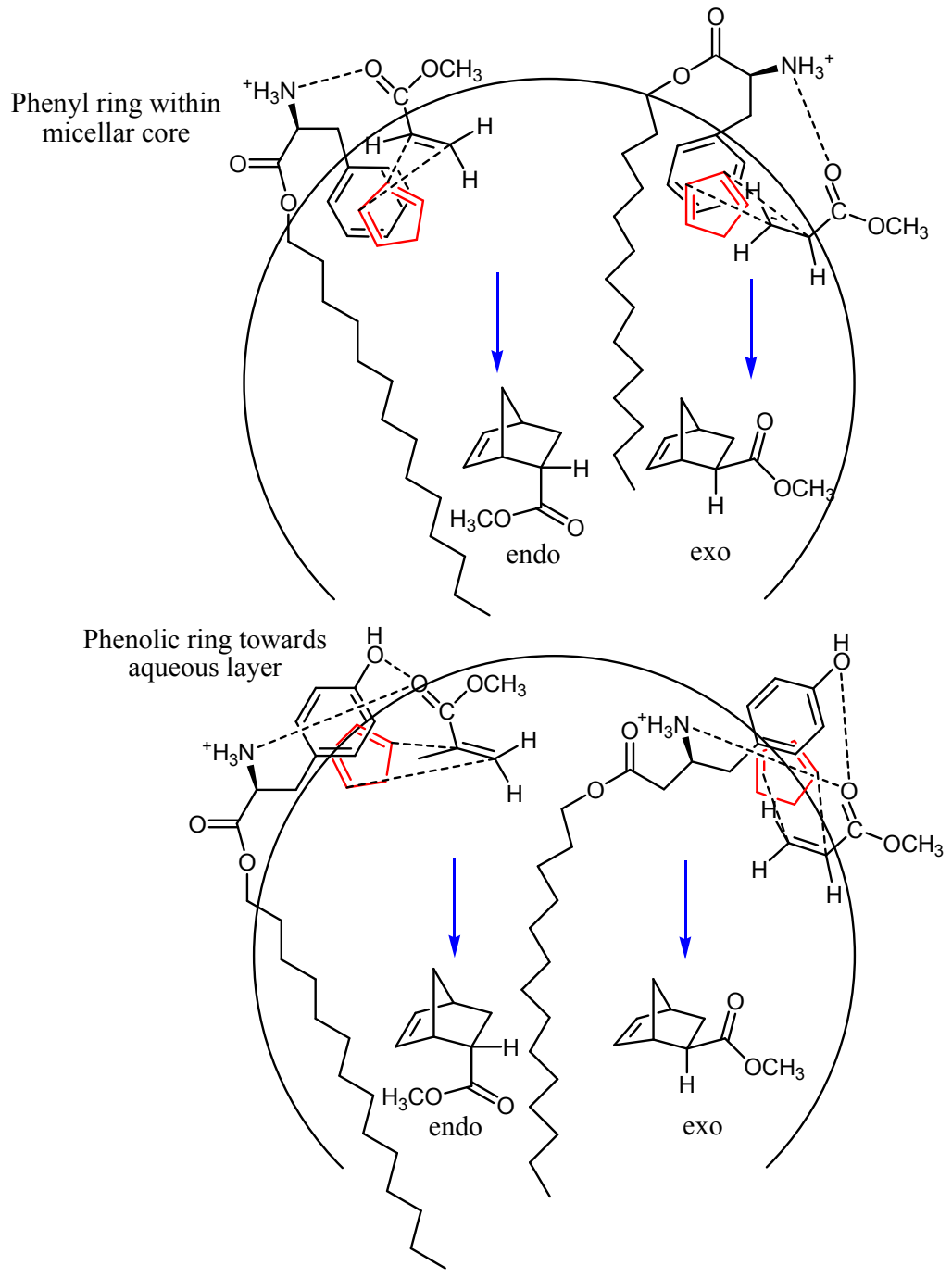

Figure 5. Postulate model showing the interactions between L-phenylalanine and L-tyrosine catalysts with cyclopentadiene and methyl acrylate. 
After the successful acceleration of the Diels-Alder reactions with cationic surfactants, the study was extended to explain how the yield and selectivity of the cyclo-adduct can be affected using different concentrations of catalysts before, at and after the critical micelle concentration of the catalyst. CTAB was initially used to study the effect of micellization on the yield and selectivity of the Diels-Alder reaction (Figure 6). At a concentration of $0.02 \mathrm{mM}$ of CTAB which is well below its $\mathrm{CMC}$, a low yield was observed. At the onset of the CMC of CTAB, an abrupt increase in the yield of the Diels-Alder adduct was observed. The yield then decreases upon further increase in concentration above the CMC of CTAB. Micellization was also found to affect the selectivity of the Diels-Alder reaction, whereby an increase in the concentration of $\mathrm{CTAB}$ to its $\mathrm{CMC}$ and above increased the ratio of the endo over the exo adduct.

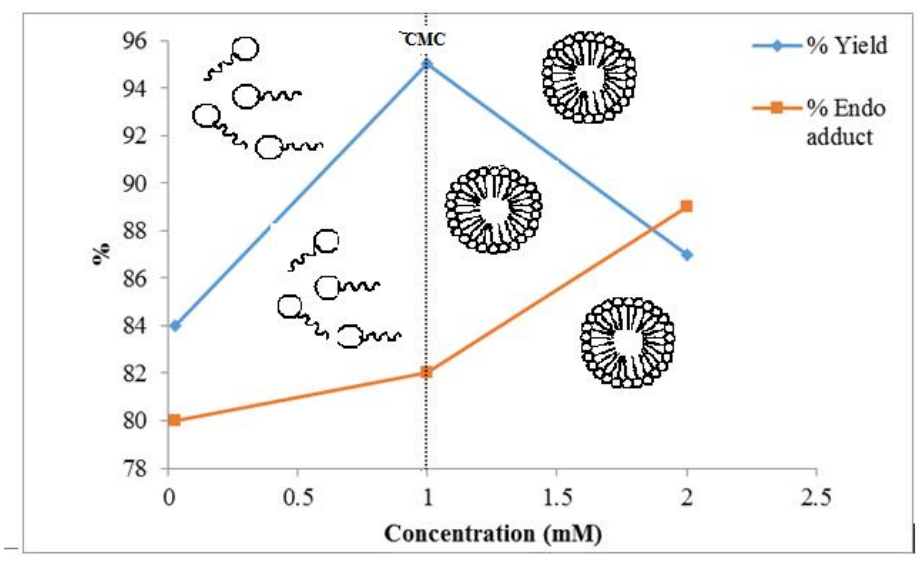

Figure 6. Effect of varying the concentration of CTAB on yield and selectivity.

The effect of micellization was also studied with the tyrosine esters. The results are shown in Table 2.

Table 2. Influence of CMC value on the yield and selectivity of the reaction between cyclopentadiene and methyl acrylate-water, $72 \mathrm{~h}, 20{ }^{\circ} \mathrm{C}$.

\begin{tabular}{|c|c|c|c|c|}
\hline Entry & Surfactant & Conditions & Yield (\%) & Endo : Exo \\
\hline 1 & Tyr10 & $0.5 \times$ CMC & 24 & $83: 17$ \\
\hline 2 & Tyr10 & CMC & 71 & $80: 20$ \\
\hline 3 & Tyr10 & $4 \times$ CMC & 3 & $86: 14$ \\
\hline 4 & Tyr12 & CMC & 44 & $85: 15$ \\
\hline 5 & Tyr12 & $4 \times$ CMC & 22 & $88: 12$ \\
\hline 6 & Tyr14 & CMC & 34 & $85: 15$ \\
\hline 7 & Tyr14 & $4 \times$ CMC & 34 & $85: 15$ \\
\hline
\end{tabular}

All the tyrosine esters showed similar trends as that observed with CTAB. When their concentrations are below their respective CMC values, the surfactants exist in the monomeric form. At the CMC, a steady increase in the yield of the Diels-Alder adduct was observed due to the formation of micelles in the reaction medium, which helped in the solubilization and orientation of the reactants within the micellar core, hence favouring the yield and selectivity of the reaction. A further increase in the concentration above the CMC values resulted in greater selectivity of the Diels-Alder adduct towards the endo product. This might be due to a change in 
the shape of the micelles when the concentration of the surfactant is increased well above its CMC [33] which favoured the kinetic endo product over the thermodynamic one. However, at this particular concentration, a drop in the yield of the product was observed which might be explained by the change in the micellar structure which rendered the reaction unfavorable.

The $\mathrm{pH}$ of the reaction medium has been known to play a vital role in the yield and selectivity of the product $[20,34]$. The effect of $\mathrm{pH}$ was investigated using CTAB and dodecyl tyrosine ester hydrochloride in water (Table 3 ). The $\mathrm{pH}$ was adjusted by dropwise addition of 2 $\mathrm{M} \mathrm{HCl}(\mathrm{pH}<3)$ or $2 \mathrm{M} \mathrm{NaOH}(\mathrm{pH}>3)$ and was monitored using a $\mathrm{pH}$ meter. At extreme acidic conditions, $\mathrm{pH} 1$, the cyclo-adduct was obtained in only $13 \%$ yield. This can be attributed to the breakdown of self-aggregates of the micelles. Increasing the $\mathrm{pH}$ to 3 was found to enhance both the yield and selectivity of the product (entry 2, Table 3 ). This is in line with previous studies whereby it was reported that $\mathrm{pH} 3$ provides favourable polarization of the acrylate molecule in protic media stabilizing the micellar aggregates [20]. At higher $\mathrm{pH}$, surfactants exist as the free amine and can form hydrogen bonding with the acrylate which is no longer protonated, thus stabilizing the reactive intermediates and hence favoring the reaction and also the preferential formation of the thermodynamically stable exo isomer.

The effects of using a salting-out agent was also investigated. $\mathrm{LiCl}$ was added as a salting out agent which helped remove the reactants from the aqueous pseudo-phase, increasing the complexation of the substrate to the micelles. Moreover, increasing concentration of chloride counter ions caused a shrinkage in the Stern layer (region in the micelle which contains the polar head groups as well as counter ions tightly bound that interact with the aqueous exterior) which lead to a greater pre-orientation thus forcing the reactants to come closer thus resulting in enhanced yield (Table 3, entry 6). As expected, the reaction yield of the cycloadduct increased to $84 \%$. However, a large drop in the endo/exo ratio was observed showing that the production of the exo isomer was favoured.

Table 3. Variation of $\mathrm{pH}$ and salting-out agent on the reaction between cyclopentadiene and methylacrylatewater, $72 \mathrm{~h}, 20^{\circ} \mathrm{C}$

\begin{tabular}{|c|c|c|c|c|c|}
\hline Entry & Surfactant & $\mathrm{pH}$ & Conditions & Yield (\%) & Endo : Exo \\
\hline 1 & Tyr10 & 1 & At CMC & 13 & $83: 17$ \\
\hline 2 & Tyr10 & 3 & At CMC & 77 & $93: 7$ \\
\hline 3 & Tyr10 & 5 & CMC & 56 & $78: 22$ \\
\hline 4 & Tyr10 & 7 & CMC & 71 & $80: 20$ \\
\hline 5 & Tyr10 & 9 & CMC & 68 & $79: 21$ \\
\hline 6 & Tyr10 & 3 & At CMC $+4.86 \mathrm{M} \mathrm{LiCl}$ & 84 & $80: 20$ \\
\hline
\end{tabular}

\section{CONCLUSION}

We have demonstrated that our pre-synthesized surfactant compounds derived from L-tyrosine and L-phenylalanine are promising chiral micellar catalysts for Diels-Alder reactions. We also compared and carried out for the first time a comparative catalytic study of these amino acid surfactants with cationic $\mathrm{CTAB}$ under varying conditions. The $\mathrm{C}_{10}$ derivatives for both phenylalanine and tyrosine generated higher yields (up to 98\%) and selectivities (high endo/ratio up to $92 \%$ ) of the Diels-Alder product. The ester hydrochloride surfactants showed optimum activity when used at a concentration corresponding to their respective CMC values, under an acidic condition $(\mathrm{pH}=3)$ as well as in the presence of $\mathrm{LiCl}$ as salting-out agent. 
The use of optically active $O$-alkyl ester hydrochlorides of L-phenylalanine and L-tyrosine 517

\section{ACKNOWLEDGEMENTS}

We are grateful to the following technical staff at the University of Mauritius: Mrs. S. L'Omelette-Moonien for the running of the NMR and Mr. Abdool Cader Dawoojee Wahed for running the GC-MS.

\section{REFERENCES}

1. Nicalaou, K.C.; Snyder, S.A.; Montagnon, T.; Vassilikogiamakis, G. The Diels-Alder reaction in total synthesis. Angew. Chem. Int. Ed. 2002, 41, 1668-1698.

2. Magano, J. Synthetic approaches to the Neuraminidase inhibitors Zanamivir (Relenza) and Oseltamivir phosphate (Tamiflu) for the treatment of influenza. Chem. Rev. 2009, 109, 4398-4438.

3. Nishimoto, K.; Okada, Y.; Kim, S.; Chiba, K. Rate acceleration of Diels-Alder reactions utilizing a fluorous micellar system in water. Electrochim. Acta 2011, 56, 10626-10631.

4. Ghadari, R. In silico study to evaluate the governing criteria in the $\mathrm{BF}_{3}$ catalysed DielsAlder reaction. Comp. Theor. Chem. 2016, 1091, 176-185.

5. Miller, J.P. Advances in Chemical Research, Nova Science Publications: New York; 2013; pp. 179-219.

6. Erfurt, K.; Wandzik, I.; Walczak, K.; Matuszek, K.; Chrobok, A. Hydrogen-bond-rich ionic liquids as effective organocatalysts for Diels-Alder reaction. Green Chem. 2014, 16, 35083514.

7. Marković, Z.; Predojevic, J.; Manojlovic, N.T. Synthesis of $\mathrm{C}_{7}-\mathrm{C}_{16}$-alkyl maltosides in the presence of tin(IV) chloride as a Lewis acid catalyst. Bull. Chem. Soc. Ethiop. 2011, 25, 8390 .

8. Mosaddegh, E.; Hassankhani, A. One-pot synthesis of polyhyropyridine derivatives via Hantzsch four component condensation in water medium: use of a recyclable Lewis acid $\left[\mathrm{Ce}\left(\mathrm{SO}_{4}\right)_{2} .4 \mathrm{H}_{2} \mathrm{O}\right]$ catalyst. Bull. Chem. Soc. Ethiop. 2012, 26, 461-465.

9. Kobayashi, S.; Manabe, K. Green Lewis acid catalysis in organic synthesis. Pure Appl. Chem. 2000, 72, 1373-1380.

10. Kumar, B.; Tikariha, D.; Ghosh, K.K.; Barbero, N.; Quagliotto, P. Kinetic study on effect of novel cationic dimeric surfactants for the cleavage of carboxylate ester ester. J. Phys. Org. Chem. 2013, 26, 626-631.

11. Ghosh, K.K.; Kolay, S.; Bal, S.; Satnami, M.; Quagliotto, P. Effect of cationic gemini surfactants on the hydrolysis of carboxylate and phosphate esters using hydroxamate ions. Colloid. Polymer. Sci. 2008, 286, 293-303.

12. El Seoud, O.A. Effects of organized self assembly on acid-base equilibria. Adv. Colloid. Interface Sci. 1989, 30, 1-30.

13. Bunton, C.A. Reactivity in aqueous association colloids: Descriptive utility of the pseudophase model. J. Mol, Liq. 1997, 72, 231-249.

14. Tiascoglu, T. Micellar solutions as reaction media. Tetrahedron 1996, 52, 11113-11152.

15. Grieco, P.A.; Garner, P.; He, Z. Micellar catalysis in the aqueous intermolecular Diels-Alder reaction: Rate acceleration and enhanced selectivity. Tetrahedron Lett. 1983, 24, 1897-1900.

16. Braun, R.; Schuster, F.; Sauer, J. (4+2)-Cycloadditionen in micellen: ein vergleich des producktspektrums und der reaktionsgeschwindigkeit mit reaktionen in lösung. Tetrahedron Lett. 1986, 27, 1285-1288.

17. Singh, V.K.; Raju, B.N.; Deota, P.T. Micellar catalysis $\pi^{4 \mathrm{~S}}+\pi^{2 \mathrm{~S}}$ cycloaddition in aqueous media. Synth. Comm. 1988, 18, 567-574.

18. Breslow, R.; Maitra, U.; Rideout, D.C. Selective Diels-Alder reactions in aqueous solutions and suspensions, Tetrahedron Lett. 1983, 24, 1901-1904.

19. Grieco, P.A, Garner, P.P.; Organic synthesis in water. London: Blacky Academic and Professional: London; 1998; pp.1-46. 
20. Diego-Castro, M.J.; Hailes, H.C. Novel application of chiral micellar media to the DielsAlder reaction. Chem. Commun. 1998, 15, 1549-1550.

21. Joondan, N.; Jhaumeer-Laulloo, S.; Caumul, P. A study of the antibacterial activity of Lphenylalanine and L-tyrosine esters in relation to their CMCs and their interactions with 1,2dipalmitoyl-sn-glycero-3-phosphocholine, DPPC as model membrane. Microbiol. Res. 2014, $169,675-685$.

22. Cativiela, C.; Figueras, F.; Fraile, J.M.; Garcia, J.L.; Mayoral, J.A.; de Menorval, L.C.; Pires, E. Heterogeneous Catalysis and Fine Chemicals III, Elsevier: Amsterdam; 1993.

23. Mukerjee, $P$. The nature of the association equilibria and hydrophobic bonding in aqueous solutions of association colloids. Adv. Colloid Interface Sci. 1967, 1, 241-275.

24. Diego-Castro, M.J.; Hailes, H.C. Studies on the use of surfactants in aqueous Diels-Alder reactions. Tetrahedron Lett. 1998, 39, 2211-2214.

25. Goto, A.; Takemoto, M.; Endo, F. A thermodynamic study on micellization of nonionic surfactant in water and in water-ethanol mixture by gel filtration. Bull. Chem. Soc. Jpn. 1985, 58, 247-251.

26. Woodward, R.B.; Baer, H. The reaction of furan with maleic anhydride. J. Am. Chem. Soc. 1948, 70, 1161.

27. Attwood, D.; Florence, A.T. Surfactant Systems, Springer: Netherlands; 1983; pp.72-123.

28. Rossen, M.J.; Kunjappu, J.T. Surfactants and Interfacial Phenomena, Wiley: New Jersey; 2012; pp.123-191.

29. Sousa, C.A.; Rodríguez-Borges, J.E.; Friere, C. New L-Serine derivative ligands as cocatalysts for Diels-Alder reaction. Organic Chemistry 2013, 2013, Article ID 217675, 1-5. DOI: http://dx.doi.org/10.1155/2013/217675.

30. Vijay, R.; Angayarkanny, S.; Baskar, G. Amphiphilic dodecyl ester derivatives from aromatic amino acids: significance of chemical architecture in interfacial adsorption characteristics. Colloids and Surfaces A: Physicochem. Eng. Aspects 2008, 317, 643-649.

31. Vijay, R.; Singh, J.; Baskar, G.; Ranganathan, R. Amphiphilic lauryl ester derivatives from aromatic amino acids: significance of architecture in aqueous aggregation properties. $J$. Phys. Chem. B. 2009, 113, 13959-13970.

32. Vijay, R.; Mandal, A.B.; Baskar, G. ${ }^{1} \mathrm{H}$ NMR spectroscopic investigations on the conformation of amphiphilic aromatic amino acid derivatives in solution: effect of chemical architecture of amphiphiles and polarity of solvent medium. J. Phys. Chem. B. 2010, 114, 13691-13702.

33. Aswal, V.K.; Goyal, P.S.; Thiyagarajan, P. Small-angle neutron-scattering and viscosity studies of CTAB/NaSaI viscoelastic micellar solutions. J. Phys. Chem. B. 1998, 102, 24692473.

34. Mubofu, E.B.; Engberts, J.B.F.N. Surfactant-assisted specific acid catalysis of Diels-Alder reactions in aqueous media. J. Phys. Org. Chem. 2007, 20, 764-770. 